\title{
Relación de Méritos y Servicios de Morales Duárez
}

\author{
Por Daniel Valcárcel
}

Entre los grandes representantes de la generación de criollos nacidos en la segunda mitad del siglo XVIII, Vicente Morales Duárez ocupa lugar distinguido. Jurista y Catedrático sanmarquino, pasa a España, se transforma en político y ocupa puestos de gran importancia, falleciendo en 1812 cuando desempeñaba el cargo de Presidente de las Cortes de Cádiz. (1)

La presente Relación es un impreso en dos fojas, existente en el Archivo General de Indias, (Audiencia de Lima, Legajo 1048), (2) con noticias básicas para su biografía. Comprende desde su nacimiento ( Lima ${ }^{24} \mathrm{Cl}^{\mathrm{l}-1755)}$ ) hasta el reconocimiento de sus servicios (Madrid, 15-VII-1794) y un añadido manuscrito correspondiente a una Real Orden (3-V-1797) ratificatoria de sus eminentes méritos personales e importantes servicios. (3)

Sevilla, IV-1957.

DANIEL VALCARCEL.

RELACION/ DE LOS MERITOS,/ Y SERVICIOS/ DEL DOCTOR/ D. VICENTE MORALES DUAREZ DE LA QUADRA,/ Abogado de la Real Audiencia de Lima, y Catedrático/ de Instituta en aquella Real Universidad (4)

Es, según se ha hecho constar, natural de la misma Capital de Lima: de edad de treinta y nueve años cumplidos: hijo legítimo del Capitán D. Vicente Antonio Morales, natural de la Ciudad de Granada, y de Doña María Mercedes Duarez de la Qua- 


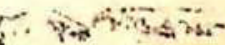

dra, oriunda de la propia Ciudad: nieto con igual legitimidad por la línea paterna de D. Christobal Santisteban y Morales, y de Doña Andrea Segura y Franco; y por la materna de D. Melchor Duarez de la Quadra, y de Doña Ursula Sayagos, sugetos todos de conocida distinción, tenidos, y reputados por nobles, habiendo habido varios entre su familia que han obtenido honoríficos empleos, así políticos, como militares, y del Santo Oficio.

Fué Colegial en el Real Convictorio de San Cárlos de la referida Ciudad de Lima, donde siguió la carrera literaria con aprovechamiento.

En veinte y siete de Marzo de mil setecientos setenta y tres (5) defendió extemporaneamente, y sin prevención alguna, á presencia del Virrey, Audiencia, y demas Cuerpos, y Tribunales, un acto público del primer año del curso de Teología que prescriben los nuevos Estatutos (6) de aquella Real Universidad.

En ella recibió el grado de Bachiller en Artes en diez y nueve de Mayo de mil setecientos setenta y tres, y precedidos otros diferentes actos públicos, y los demas requisitos acostumbrados, se graduó de Bachiller, Licenciado, y Doctor en Teología en treinta y uno de Octubre de mil setecientos setenta y cinco, y catorce de Febrero siguiente; $y$ en veinte y tres de Noviembre de mil setecientos setenta y ocho se le confirió el de Bachiller en Sagrados Cánones.

Instruído también en la Jurisprudencia práctica, y precedido el exámen, y demas requisitos acostumbrados, se recibió de Abogado en dicha Real Audiencia de Lima en siete de Junio de mil setecientos setenta y nueve.

En once de Diciembre de mil setecientos ochenta le nombró (ff.l.v.) el Señor Visitador general que fué del Perú D. Joseph Antonio de Areche por Asesor de la Renta de Tabacos, en atención á haberle cometido por providencias particulares, en calidad de interino, varios negocios de la misma Renta, que se hallaba desempeñando completamente, acreditando en ello su literatura, y buena conducta. Mientras sirvió este destino se incorporaron á dicha Renta, en virtud de Real Orden, los ramos estancados de Naypes, Pólvora, Breas, y Papel Sellado, con cuyos agregados continuó desempeñando su ministerio hasta fines del año de mil setecientos ochenta y tres, en que se determinó por aquella Superintendencia general de Real Hacienda, quedase dicha Asesoría agregada á uno de los Subdelegados de Visita, y 
$\in$ n este concepto fué nombrado por tal D. Melchor de Foncerrada, Oidor actual de la Real Audiencia de Santo Domingo.

Asimismo consta, que habiéndole nombrado el Ayuntamiento de la Ciudad de Lima como Asesor en diferentes ocasiones, acreditó el concepto público que goza, desempeñando felizmente la substanciación, y resolución de las causas que se le confiaron.

En los años de mil setecientos ochenta y dos, y mil setecientos ochenta y ocho hizo oposición a las Cátedras de Prima de Cánones, y Leyes propias de la expresada Real Universidad de Lima, desempeñando con exáctitud los exercicios de lección de hora y media, y réplicas de sus Coopositores. (7)

En iguales términos hizo posteriormente nueva oposición a la Cátedra de Instituta, para la qual salió electo por exceso de treinta y dos votos, $\mathrm{y}$ en su conseqüencia le dió posesión en quince de Julio de mil setecientos noventa y dos el Rector de dicha Real Universidad, quien en veinte de Junio del mismo año le nombró por Bibliotecario de ella, con-respecto á concurrir en su persona todas las calidades, y circunstancias necesarias al buen desempeño de esta Comisión.

Posesionado en su Cátedra de Instituta, promovió Expediente para que se declarase, si para continuar en ella necesitaba, segun lo prevenido en las Constituciones de aquella Real Escuela, el grado mayor de Leyes, ó si le bastaba el de Bachiller en esta Facultal (sic) con el de Doctor, que obtenía en Teología. En su vista determinó el Virrey c conformeo al/votooconsultivo del Real Acuerdo, que en atención al particular mérito del expresado D. Vicente Morales, pruebas repetidas que tenía dadas de su literatura, aceptación que la misma Real Universidad había hecho de sus servicios, y voluntad que tenía manifestada de premiarle, sin sujetarle al gravamen de los costos del grado, estando en costumbre estos indultos aun sin concurrir circunstancias tan relevantes, se le confiriese dicho grado en un solo acto, sin gravamen ,ni pensión alguna: todo lo qual tuvo su debido cumplimiento en veinte y uno de Febrero de mil setecientos noventa y tres.

Con fechas de trece de Enero, y trece de Marzo del propio año de mil setecientos noventa y tres informaron á $S$. $M$. en favor de este interesado la Real Audiencia, y Universidad de $\mathrm{Li}$ ma, expresando aquellas, que á su buen nacimiento acompaña buenas cos-/ (ff. 2) tumbres, y unos talentos calificados en diferentes especies de literatura, como lo manifiestan su grado de Doctor, Titulo de Catedrático, y el notorio juicio con que ha de- 
sempeñado siempre los objetos de su, profesion, así en diferentes Asesorías, como en las defensas civil, y criminal de pobres que le comisionó por dos años, y en las muchas causas de entidad, y consideración que le encarga el público ;por cuyas consideraciones le recomienda como benemérito para obtener alguna de las confianzas y honrosas colocaciones en que S. M. quiera destinarle.

Igualmente expresa la Universidad en su respectivo informe, que el referido D. Vicente Morales ha cultivado con esmero todas las Facultades mayores, y los ramos de literatura, apreciada en aquel Pais, con especialidad la Teología, y Jurisprudencia: Que en el año de setenta y dos fué elegido por el Real Convictorio de San Cárlos para consagrar al Señor Rey D. Cárlos III. el primer fruto de los nuevos Planes de Estudios formados con arreglo á las Reales Ordenes, cuya función presenciaron con universal aplauso el Virrey, Audiencia, Cabildos, y demas Cuerpos públicos: Que constituido despues de Maestro, y Colegial mayor en el citado Colegio, se dedicó á formar un crecido número de Jóvenes por el mismo nuevo Plan, de cuyo feliz progreso ha dado repetidas pruebas. $Y$ finalmente, que por sus incesantes servicios, así en aquella Universidad con sus continuas Presidencias, actos, y oposiciones, como en el público, desempeñando con el mayor crédito sus confianzas de foro, y diferentes Asesorías, y Comisiones particulares, se le confirió el grado de Doctor en Teología, la Cátedra de Instituta y el empleo de Bibliotecario, con la particular circunstancia de que para el grado de Leyes, y Cánones precedió un auto del Real Acuerdo para que se hiciese esta concesión por indulto, mediante su mérito público; cuyas calidades, que le acreditan de un Literato de distinguido aprecio, y por ello ha sido escogido por la reciente Academia de Amantes del Pais, destinada al mayor fomento de las letras, le hacen verdaderamente digno de la Real clemencia de S. M. para que le coloque en mayores destinados, que desempeñará con rectitud, acierto, y la mayor satisfaccion de aquel Cuerpo.

Formóse en la Secretaría del Supremo Consejo, y Cámara de Indias por lo tocante al Perú, y lo Indiferente, de los citados informes que quedan (en) ella, y de otros varlos documentos, exhibidos por parte del interesado, á quien se volvieron. Madrid, y Julio quince de mil setecientos noventa y quatro.

(fdo.) Antonio de Medina. (una rúbrica) 
(ff. 2v.) MERITOS, Y SERVICIOS/ DEL DOCTOR DON VICENTE MORALES,/ natural de la Ciudad de Lima.

Hijo de legítimo matrimonio, y de fámilias distinguidas, así por linea paterna, como por la materna.

Colegial en el Real Convictorio de San Cárlos de Lima, donde siguió la carrera literaria con aprovechamiento, teniendo varios actos públicos en aquella Real Universidad.

Grados de Bachiller en Ârtes, y Sagrados Cánones.

Grados de Bachiller, Licenciado, y Doctor en Teología.

Abogado de la Real Audiencia de Lima.

Asesor de la Renta de Tabacos, cuyo empleo sirvió con varios agregados, hasta que se mandó corriese a cargo de uno de los Subdelegados de Visita.

Asesor en diferentes ocasiones del Ayuntamiento de Lima.

Asesor de la Renta de Tabacos, cuyo empleo sirvió con varios agregados, hasta que se mandó corriese á cargo de uno de los Subdelegados de Visita.

Asesor en diferentes ocasiones del Ayuntamiento de Lima.

Ha hecho varias oposiciones a las Cátedras de aquella Real Universidad. ella.

Es actualmente Catedrático de Instituta, y Bibliotecario de

Por su notorio mérito se le concedió por indulto el grado de Doctor en Leyes, y Cánones, precedido un Auto del Real Acuerdo.

Informes de Ja citada Real Audiencia Y Universidad de Lima, en que así por su calidad, conducta, y literatura, como por lo bien que ha desempeñado los referidos destinos, le contemplan digno de ser atendido.

En Real Orden/ de 3 de Mayo/ de 1797 se previ/ no á la Camara/ atendiese á este/ sugeto, segun su/merito, lo q.e man/ dó dho tribunal/ se hiciese preste/ por acuerdo de/ 8 del propio mes.

(1) v. Vicente Morales Duárez, maestro, jurista y político liberal por D. V. (Rev. Letras, nos. 54-55, ler.-2\% semestre 1955, pp. 129-142). Contiene una Introducción, un Escorzo bibliográfico, donde son señalados los diversos libros y Artículos dedicados al estudio del prócer limeño, una Reseña biográfica, que distingue las diversas etapas de su existencia y sus principales sucesos. El trabajo se complementa con un Arbol genealógico, dos Retratos de Morales Duárez y las Portadas del Elogio que éste pronunció en honor del prelado Manuel Joaquín Gonzá- 
lez Acuña Sanz y Merino (Lima, Imprenta de la Real Casa de Niños Expósitos, 1803) y los Honores Patrios hechos por el Cabildo de Lima al saberse su fallecimiento (Lima, Imprenta de los Huérfanos, 1812).

(2) v. Documentos de la Audiencia del Cusco en el A. G. I. por D. V. (Lima, Imprenta San Marcos, 1957). Contiene referencias a 82 Legajos existentes en el repositorio sevillano, desde mediados de la segunda mitad del siglo XVIII, hasta finalizar el primer cuarto del siglo XIX.

(3) Bibliografia de V. M. D. ...

Elogio/Del/Ilustrísimo Señor Doctor/Don Manuel Joaquin Gonzalez Acuña Sanz/y Merino, Dignísimo Obispo de/Panamá./Pronunciado/En la Dedica del Acto Ge-/neral de Filosofia, que consagró a dicho/Señor el Colegial del Real Convictorio/de San Carlos Don Marcelino Cavero y/Tagle, en la Real Universidad de San/Marcos de Lima, el dia 31 del próximo Agosto./Por /El Doctor Don Vicente Mo-/rales, Catedrático de Decreto en dicha/Real Universidad, y Doctor en Teología/y ambos Derechos./Impreso en Lima, en la Imprenta de la Real/Casa de Niños Expósitos. Año de 1803.

Elogio académico/del/Excelentísimo é Ilustrísimo Señor/Doctor Don Juan Domingo Gonzalez de la Reguera/del Consejo de S. Mag., Caballero Gran-Cruz de/la Real y Distinguida Orden Española de Cárlos/III, Dignísimo Arzobispo de la Santa Iglesia/de Lima:/Pronunciado/en el acto literario que para ob-/tener el grado de Doctor en Teologia, le dedicó/ Don Tomás Joseph de la Casa y Piedra, Colegial/Maestro del Real Seminario de Santo Toribio,/en la Real Universidad de San Marcos,/el dia 21 de Junio de 1805./Por/Don Vicente Moráles, Abogado de/esta Real/ Audiencia, Doctor en Teologia y en/ambos Derechos, y Catedrático de Decreto en/la misma Universidad/Lima M.DCCV./En la imprenta de la Real Casa de Huérfanos.

Medina cita una hoja impresa referente al acto académico, defendido por Morales Duárez en 1773. (La Imprenta en Lima, t. III, No. 1363, pp. 52).

Memorias de las Cortes de Cádiz (ms. extraviado, escrito por V. M. D.).

Oración Fúnebre/Del Señor/Don Vicente Morales Duárez;/Presidente/Del Soberano Congreso Nacional/Que Dixo En la Santa Iglesia Catedral/De los Reyes : En VII. De Noviembre;/El Señor Canonigo Magistral/D.D. José Manuel Bermudez./ Lima./Imprenta de los Huerfanos:/ Por D. Bernardino Ruiz./MDCCCXII.

Honores Patrios/Consagrados a La Tierna Memoria/Del Señor/Don Vicente Morales Y/Duarez,/Presidente/Del Augusto Congreso de Córtes./Por EI Excmo. Cabildo/De Esta Capital De Lima./En VII.De Noviembre De 1812./Lima: Imprenta De Los Huerfanos: 1812./Por Don Bernardino Ruiz. (Con retrato de V. M. D., "Grabado en Lima, p. Marcelo Cabello").

Alayza Paz Soldán, Luis : El egregio limeño Vicente Morales Duárez. En Revista Histórica t. XI, entregas I-II, pp. 37-92. 
: La Constitución de Cádiz de 1812. El egregio limeño Morales y Duárez. Lima, Edit. Lumen, 1946.

(Véase asimismo del citado autor, "Revista del Instituto Sanmartiniano", Lima, VII-45).

Cuentas de la Thesorería (1810-13) ms. inédito del Archivo Central de la Universidad de San Marcos.

Guía de 1793.

Lavalle, José Antonio de : Don Vicente Morales Duárez. La Revista de Lima, t. I. (Reedición póstuma en "Estudios Históricos", Lima, Lib. e Imp. Gil, 1935).

Libro XIV de Claustros de la Real y Pontificia Universidad de San Marcos (1780-1790. Ms. del Archivo Central de la Universidad de San Marcos).

Mendiburu, Manuel de : Diccionario Histórico-biográfico del Perú. (Primera edición, Lima, Imp. Bolognesi, 1885; II edición, Lima, Imp. Gil 1933).

Puertas Castro, Néstor: Julio Manuel del Portillo, liberal y castillista. En : "El Comercio", Lima, 24-VIII-1954.

Valcárcel, Daniel : El prócer Duárez en el IIo. centenario de su nacimiento. En : "El Comercio", Lima, 24-I-1955, pp. 3.

- : Homenaje a Morales Duárez y a Unanue en la Sociedad Peruana de Historia. En "El Comercio", Lima, 14-XII-1955, pp. 5. (En esta ocasión disertaron, sobre Morales Duárez D. V., y sobre Unanue, J. B. Lastres.

- Vicente Morales Duárez, Maestro, Jurista y Político liberal. En : Rev. Letras Nos. 54 y 55, Lima, Ed. San Marcos, 1955, pp. $129,42$.

- Relación de Méritos y Servicios de Morales Duárez. En : Rev. Letras No. 58, Lima, 1957 , pp. 242-248

(4) A. G. I., "Audiencia de Lima, Legajo 1048.

(5) v. Medina : La Imprenta en Lima, t. III, No. 1363.

(6) Reforma de San Marcos en la época de Amat por D. V., Apéndice. (Lima, Edit. San Marcos, 1955).

(7) cfr. Libro XIV de Claustros (1780-1790), ms. inédito del Archivo Central de la Universidad Nacional Mayor de San Marcos. 